\title{
Optical properties of TAG co-doped with Ce and Eu
}

\author{
SUMAN RANI ${ }^{1, *} \mathbb{0}$, BANSI LAL $^{2}$, SUMIT SAXENA $^{3}$ and SHOBHA SHUKLA ${ }^{3}$ \\ ${ }^{1}$ Department of Physics, School of Chemical Engineering \& Physical Sciences, Lovely Professional University, Phagwara \\ 144411, India \\ ${ }^{2}$ Sankofa Advisors, 7/604, Garden Enclave, Vasant Vihar, Thane 400610, India \\ ${ }^{3}$ Nanostructures Engineering and Modeling Laboratory, Department of Metallurgical Engineering and Materials Science, \\ IIT Bombay, Powai, Mumbai 40076, India \\ *Author for correspondence (suman.rani@lpu.co.in)
}

MS received 18 September 2018; accepted 14 December 2018; published online 8 May 2019

\begin{abstract}
Nanopowder samples of terbium aluminum garnet (TAG) doped with Ce and Eu were prepared by a sol-gel technique followed by sintering in air at various temperatures (maximum of $1100^{\circ} \mathrm{C}$ ). The investigated concentrations of both the dopants were $0.1,0.5$ and $1.0 \mathrm{~mol} \%$. Nine powder samples prepared by the permutation of the doping concentrations were characterized by scanning electron microscopy (SEM), transmission electron microscopy (TEM), energy dispersive X-ray (EDX), powder X-ray diffraction (XRD) and optical spectroscopic techniques. SEM and TEM investigations confirmed the nano-structure of the prepared powders while EDX not only confirmed the doping of Ce and Eu in TAG but also eliminated the possibility of any interfering impurities. Powder XRD showed that the basic structure of TAG did not change on doping which was further confirmed by Fourier-transform infrared studies. However, optical absorption and Raman scattering investigations showed the distortion of the TAG lattice on doping. Emission (photoluminescence) in the spectral region of 400-700 $\mathrm{nm}$ was observed when excited by $280 \mathrm{~nm}$ radiation. The intensity of this emission showed interesting dopant concentration dependence. The emission from TAG co-doped with $0.5 \mathrm{~mol} \%$ of both Ce and Eu is of particular interest as its calculated colour chromaticity coordinates ' $x$ and $y$ ' were found as $x=0.35$ and $y=0.35$ which are very close to that of sun light at noon indicating its potential as a material for the white light source.
\end{abstract}

Keywords. TAG; Ce; Eu; co-doping.

\section{Introduction}

The never-ending demand for the electrical power required for illumination has attracted the attention of the researchers to build more and more energy efficient white light sources. Recently, the advent of white light emitting diodes (LEDs) has been a turning point in illumination technology as the achievable energy efficiency of these LED sources can be $>95 \%$. Single colour emitting LEDs being easily available, output from three LEDs emitting the three primary colours (red-green-blue (RGB) scheme), can be mixed in an appropriate proportion to produce white light efficiently. However, the light used for illumination should reproduce the colours of the illuminating object faithfully; this property of a light source is measured in terms of a dimensionless quantity called 'colour rendering index (CRI) [1]'. Sunlight at noon being the best known light reproducing illuminating source has been assigned the CRI of 100; the next best being the filament lamp with the CRI of $\sim 80$. On the other hand, the CRI for a typical RGB LED white source being around 40 needs improvement. Therefore, there is a requirement of new materials for white light sources which can match the energy efficiency of LEDs and have a good CRI. One such source can be based on a single material with in-built blue light emission; this blue light can also be used to excite (in the same material), green and red emission of suitable intensity resulting in white emission. Since rare earths (RE) are known for the visible light emission it is possible to generate white light by doping these elements in various hosts [2-5]. RE can be classified into two categories: (1) broad band emitters involving $5 \mathrm{~d}-4 \mathrm{f}$ transition $\left(\mathrm{Ce}^{3+}\right.$ and $\left.\mathrm{Tb}^{3+}\right)$ and (2) narrow band emitters due to transition between $4 \mathrm{f}$ levels $\left(\mathrm{Ce}^{3+}, \mathrm{Eu}^{3+}, \mathrm{Tb}^{3+}, \mathrm{Er}^{3+}\right.$ and $\mathrm{Nd}^{3+}$ ) [6]; rare-earth with broad emission can be co-doped with the narrow emission $\mathrm{RE}$ in a suitable host to produce white light. Terbium aluminum garnet, $\mathrm{Tb}_{3} \mathrm{Al}_{5} \mathrm{O}_{12}$, (TAG) is one such host which is suitable for visible light emission along with devices like compact Faraday rotators and optical isolators due to its (i) high Verdet constant $\left(180 \mathrm{rad} \mathrm{T}^{-1} \mathrm{~m}^{-1}\right.$, room temp., $633 \mathrm{~nm}$ ) and (ii) broad transmission range (350 $1500 \mathrm{~nm})[7,8]$. However, it is difficult to prepare single crystals of TAG due to its incongruent melting properties [9]; therefore researchers are concentrating on its applications in a powder form. Recently, a number of alternative materials have been investigated for the white light emission [10,11]. 
Characteristic red emission was observed when TAG was doped with Eu [12] and Ce doped TAG resulted in yellow emission [13,14]. Batentschuk et al found energy transfer from Ce to Eu via Tb $[15,16]$ in TAG co-doped with Ce and Eu. The present study aims at investigating the optical properties of the nanopowders of TAG co-doped with $\mathrm{Ce}$ and $\mathrm{Eu}$ to assess its potential in the realization of a white light source of both the high energy efficiency and CRI.

\section{Materials and methods}

The sol-gel technique was employed for the preparation of both undoped and doped TAG nano-powders; terbium oxide $\left(\mathrm{Tb}_{4} \mathrm{O}_{7}\right)$ and aluminum nitrate $\left(\mathrm{Al}\left(\mathrm{NO}_{3}\right)_{3} \cdot 9 \mathrm{H}_{2} \mathrm{O}\right)$ being the starting materials for undoped TAG while cerium nitrate $\left(\mathrm{Ce}\left(\mathrm{NO}_{3}\right)_{3} \cdot 6 \mathrm{H}_{2} \mathrm{O}\right)$ was used for doping $\mathrm{Ce}$ and europium oxide $\left(\mathrm{Eu}_{2} \mathrm{O}_{3}\right)$ for Eu doping. The molar ratio of $\mathrm{Tb}_{4} \mathrm{O}_{7}$ to $\mathrm{Al}\left(\mathrm{NO}_{3}\right)_{3} \cdot 9 \mathrm{H}_{2} \mathrm{O}$ used in the synthesis of undoped TAG was 3:5. A clear solution of $\mathrm{Tb}_{4} \mathrm{O}_{7}$ obtained by dissolving concentrated $\mathrm{HNO}_{3}$ in the aqueous (de-ionized water) solution of $\mathrm{Al}\left(\mathrm{NO}_{3}\right)_{3} \cdot 9 \mathrm{H}_{2} \mathrm{O}$. This mixture (mixture $\mathrm{A}$ ) thus obtained was constantly stirred for about $3 \mathrm{~h}$ maintaining the temperature at $65^{\circ} \mathrm{C}$. This was followed by the addition of the citric acid (hydrated $\mathrm{C}_{6} \mathrm{H}_{8} \mathrm{O}_{7} \cdot \mathrm{H}_{2} \mathrm{O}$ ) solution which was prepared by dissolving about $0.04 \mathrm{~mol}$ of citric acid in distilled water. The whole mixture was maintained at $65^{\circ} \mathrm{C}$ and stirred continuously for about $10 \mathrm{~h}$ to obtain the sol which turned into gel by heating over a water bath. The gel thus obtained was dried at $150^{\circ} \mathrm{C}$ in an oven. This dried gel was crushed into powder and sintered in air at various temperatures (maximum of $1100^{\circ} \mathrm{C}$ ) using a home-built temperature controlled $\left( \pm 1^{\circ} \mathrm{C}\right)$ muffle furnace. The same method was used for doped samples where an appropriate amount of $\mathrm{Eu}_{2} \mathrm{O}_{3}$ solution prepared in concentrated $\mathrm{HNO}_{3}$ or aqueous solution (de-ionized water) of $\mathrm{Ce}\left(\mathrm{NO}_{3}\right)_{3} \cdot 6 \mathrm{H}_{2} \mathrm{O}$ was added to mixture $\mathrm{A}$ and rest of the procedure as outlined above was followed exactly. Samples were characterized, as mentioned earlier, by $\mathrm{X}$ ray diffraction (XRD), scanning electron microscopy (SEM), transmission electron microscopy (TEM), energy dispersive X-ray (EDX), ultraviolet-visible (UV-VIS) absorption spectroscopy, Raman scattering, Fourier-transform infrared (FTIR) and photoluminescence (PL) techniques. Powder XRD spectra at room temperature was recorded using a Philips X'perts X-ray spectrometer, while SEM images were recorded on a Joel JSM-7600F instrument. FTIR spectra were recorded using a Shimadzu, FTIR 8000 series spectrometer. A Shimadzu Model UV-VIS Absorption 1800 spectrometer

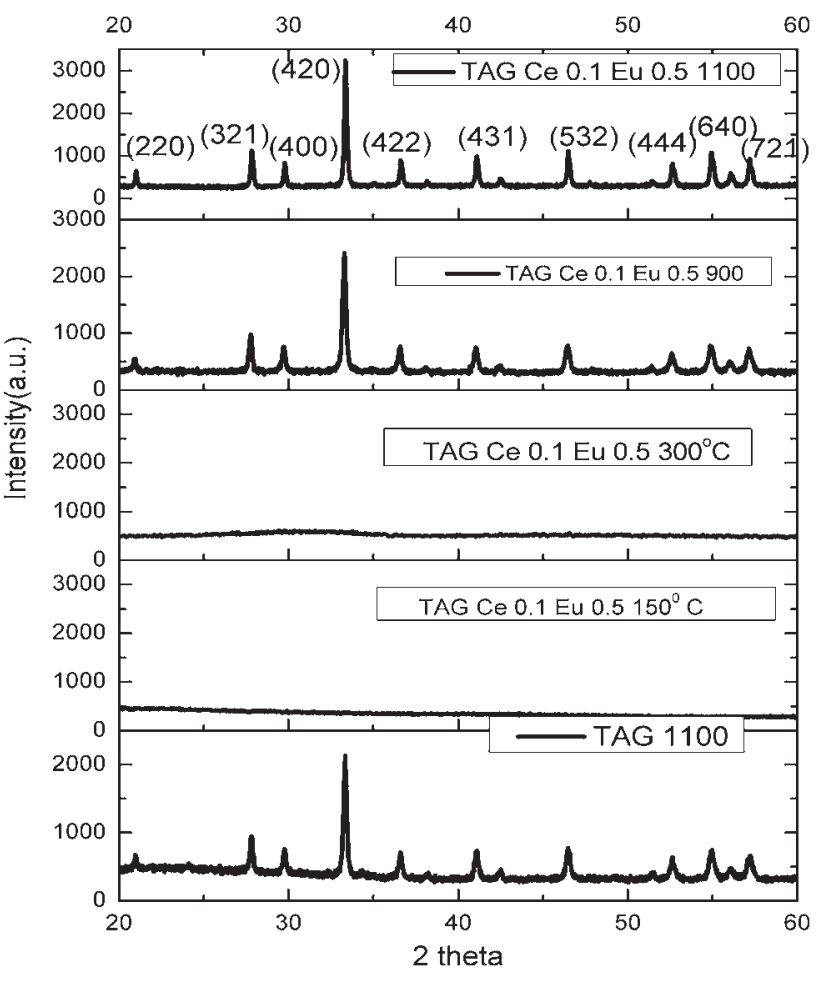

Figure 1. Typical powder XRD spectra of TAG co-doped with $0.1 \mathrm{~mol} \% \mathrm{Ce}$ and $0.5 \mathrm{~mol} \% \mathrm{Eu}$ sintered at 150, 300, 900 and $1100^{\circ} \mathrm{C}$; XRD spectra of TAG sintered at $1100^{\circ} \mathrm{C}$ are shown for comparison.

was used to record the absorption spectrum in the $200-700 \mathrm{~nm}$ region. The emission from the samples when excited with the radiation absorbed by it was recorded using the Varian Model Carry 8000 Spectrophotometer. Model Morrison, Microscope Olympus B $\times 41$ Raman spectrophotometer was used to record the Raman emission excited by $514.5 \mathrm{~nm}$ radiation from an Ar-ion laser. A JEM 2100 FTEM mode was used to record the TEM images of the samples.

\section{Results}

\subsection{Powder X-ray diffraction}

Typical powder XRD spectra of TAG co-doped with $0.1 \mathrm{~mol} \%$ $\mathrm{Ce}$ and $0.5 \mathrm{~mol} \% \mathrm{Eu}$ sintered at $150,300,900$ and $1100^{\circ} \mathrm{C}$ as a function of sintering temperature are shown in figure 1; the XRD spectrum of TAG sintered at $1100^{\circ} \mathrm{C}$ is shown for

Table 1. Typical variation of the line-width (FWHM) of the diffraction peak (420) with sintering temperature.

\begin{tabular}{lccc}
\hline S. no. & Sample (mol\%) & 2 theta $\left(^{\circ}\right)(420)$ & FWHM $\left(^{\circ}\right)$ \\
\hline 1 & TAG:Ce $(0.1)$ and Eu $(0.5)$ sintered at $900^{\circ} \mathrm{C}$ & 33.3 & 0.25 \\
2 & TAG:Ce $(0.1)$ and $\mathrm{Eu}(0.5)$ sintered at $1100^{\circ} \mathrm{C}$ & 33.3 & 0.13 \\
\hline
\end{tabular}




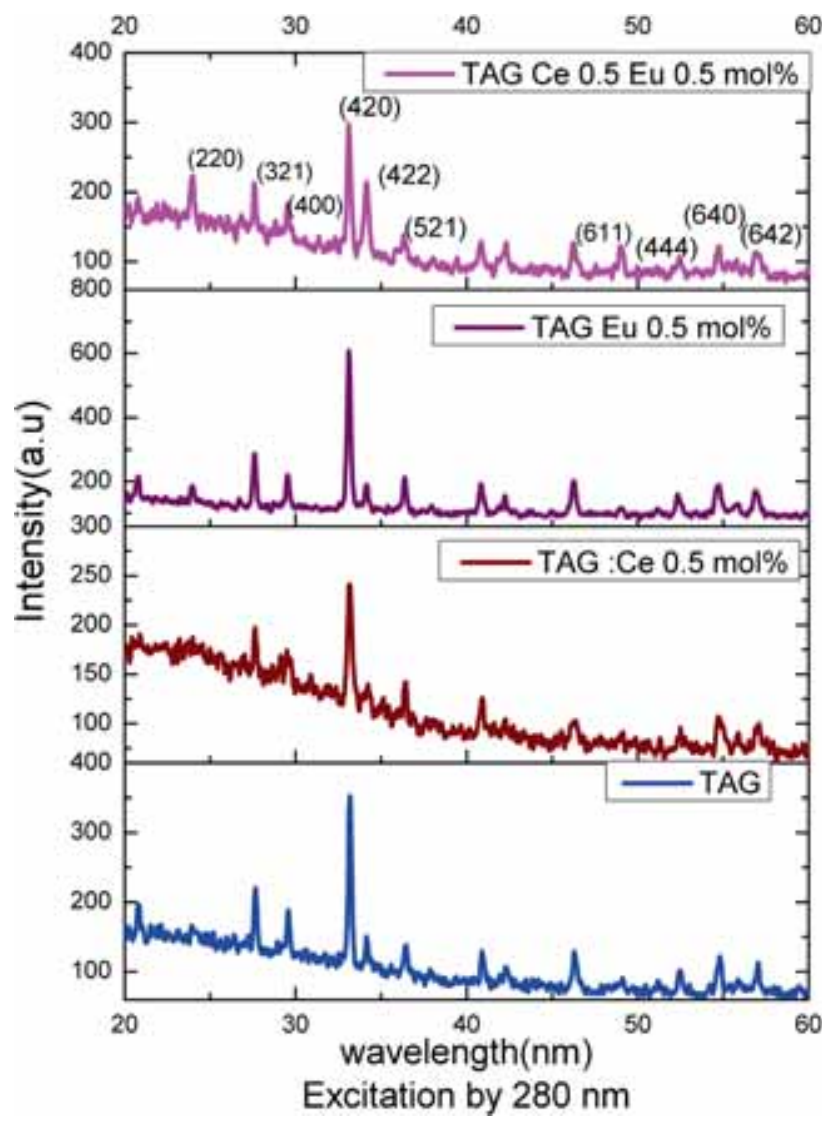

Figure 2. Comparison of the XRD spectra of TAG single doped with $0.5 \mathrm{~mol} \%$ of $\mathrm{Ce}$ and $\mathrm{Eu}$ with those of TAG co-doped with $0.5 \mathrm{~mol} \%$ of Ce and Eu.

comparison. As seen in figure 1, the prepared material was amorphous in nature at $150^{\circ} \mathrm{C}$, developed some crystallinities at $300^{\circ} \mathrm{C}$ which further improved at higher sintering temperatures. The narrowing of diffraction peaks was observed with an increase in sintering temperature and is summarized in table 1. As seen in this table the full width at half maximum (FWHM) of the diffraction peak with $(h k l)$ values $(420)$ of TAG powder (co-doped with $\mathrm{Ce}(0.1 \mathrm{~mol} \%)$ and $\mathrm{Eu}(0.5$ mol\%)) sintered at $900^{\circ} \mathrm{C}$ almost doubled when the sintering temperature was increased to $1100^{\circ} \mathrm{C}$. This is well known phenomena observed in solids mainly due to agglomeration.
The crystallite size was calculated using the Scherrer formula (equation 1)

$$
D=K \lambda / B \cos \theta
$$

where $D$ is the mean crystalline size in nm, $K$ is a dimensionless constant usually taken as $0.9, \lambda$ is the wavelength $(\mathrm{nm})$ of X-ray radiation used to record the diffraction pattern, $B$ is FWHM (rad) of any peak in the XRD pattern and $\theta$ is the angle $\left(^{\circ}\right)$ between the incident and diffracted beams.

Figure 2 shows the comparison of the XRD spectra of TAG single doped with $0.5 \mathrm{~mol} \%$ of $\mathrm{Ce}$ and $\mathrm{Eu}$ with those of TAG co-doped with $0.5 \mathrm{~mol} \%$ of $\mathrm{Ce}$ and $\mathrm{Eu}$. The parameters like peak position and crystallite size for the diffraction peak (420) calculated from the analysis of the spectra shown in figure 2 are summarized in table 2 . As seen in this table, the peak position of the (420) peak for undoped TAG is at $33.33^{\circ}$ which increases to $33.36^{\circ}$ when TAG is doped with $0.5 \mathrm{~mol} \%$ Ce. On the other hand, in TAG:Eu $(0.5 \mathrm{~mol} \%)$ the peak position of this diffraction peak shifted by $\sim 0.28^{\circ}$ towards lower angle implying the significant induction of lattice distortion by 0.5 mol\% doping of Eu in TAG. The observed shifts for TAG:Ce $(0.5 \mathrm{~mol} \%)$ and $\mathrm{Eu}(0.5 \mathrm{~mol} \%)$ increase marginally compared to TAG:Eu (0.5 mol\%) implying that co-doping of $\mathrm{Ce}$ and $\mathrm{Eu}$ reduced distortion compared to that of single doping.

The free ion radius of $\mathrm{Ce}^{3+}$ is $101 \mathrm{pm}$ while it is 93 and 97 $\mathrm{pm}$ for $\mathrm{Tb}^{3+}$ and $\mathrm{Eu}^{3+}$, respectively. Since the ionic radius of $\mathrm{Tb}$ is very close to that of Eu while it is smaller in comparison with that of $\mathrm{Ce}$. It is expected that $\mathrm{Ce}$ doping could introduce more lattice distortion compared to Eu while XRD analysis also showed the same result as expected that lattice distortion induced by $\mathrm{Ce}$ is more than that of Eu which resulted in lower degree of crystallinity in the doped TAG powder sample.

\section{$3.2 E D X$}

A typical EDX spectrum of TAG co-doped with (sintered at $\left.110^{\circ} \mathrm{C}\right) 0.5 \mathrm{~mol} \%$ of Ce and Eu is shown in figure 3 . As seen in this figure, peaks due to $\mathrm{Eu}$ and $\mathrm{Ce}$ are prominently observed along with those of $\mathrm{Tb}$ and $\mathrm{Al}$ confirming the incorporation of the dopants in the TAG lattice. The peak due to $\mathrm{Au}$ is because of the gold sample holder used for recording the EDX spectrum. Also, EDX spectra did not show any interfering impurity.

Table 2. Comparison of the crystallite size of the diffraction peak (420) of TAG single doped with $0.5 \mathrm{~mol} \% \mathrm{Ce}$ and Eu with that of TAG co-doped with $0.5 \mathrm{~mol} \%$ of $\mathrm{Ce}$ and $\mathrm{Eu}$.

\begin{tabular}{lcc}
\hline Sample sintered at $1100^{\circ} \mathrm{C}(\mathrm{mol} \%)$ & 2 theta $\left(^{\circ}\right)$ & Crystallite size $(\mathrm{nm})$ \\
\hline TAG & 33.33 & 40 \\
TAG:Ce $(0.5)$ & 33.36 & 9 \\
TAG:Eu $(0.5)$ & 33.13 & 31 \\
TAG:Ce $(0.5)$ and $\mathrm{Eu}(0.5)$ & 33.11 & 20 \\
\hline
\end{tabular}


Full scale counts: 5418

Cursor: $10.221 \mathrm{keV}$

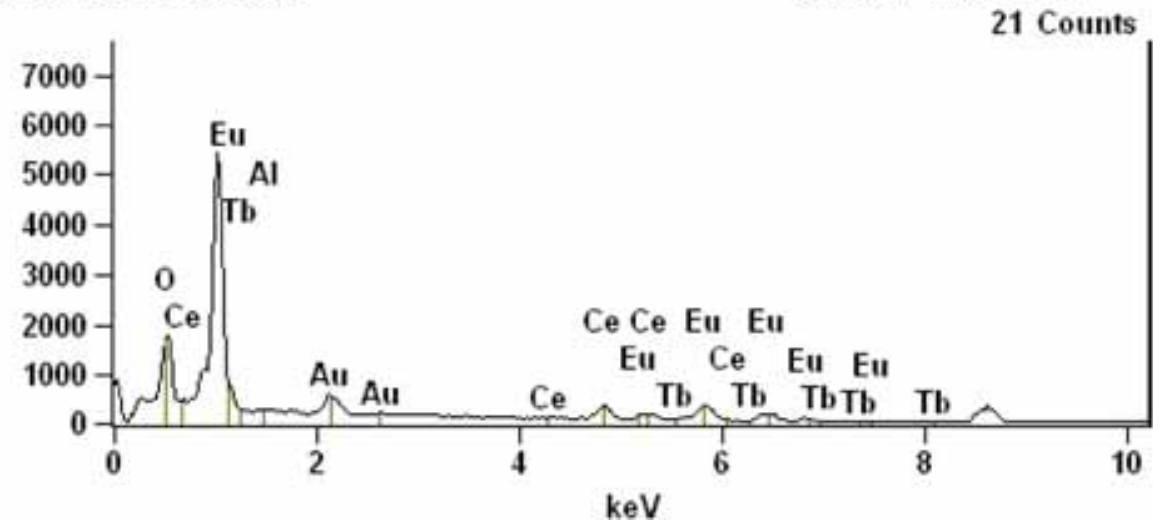

Figure 3. EDX spectra of TAG co-doped with $0.5 \mathrm{~mol} \%$ of $\mathrm{Ce}$ and Eu.

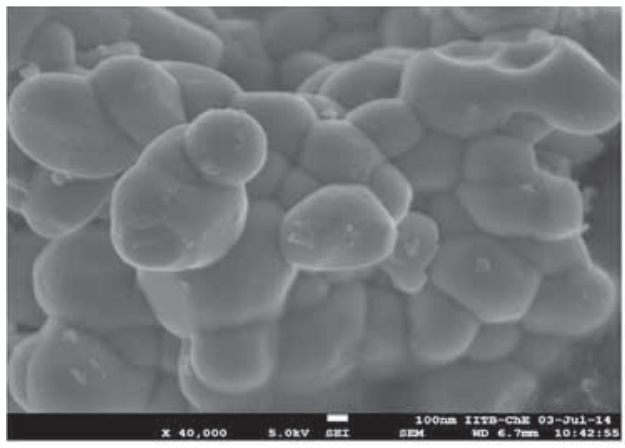

(a)

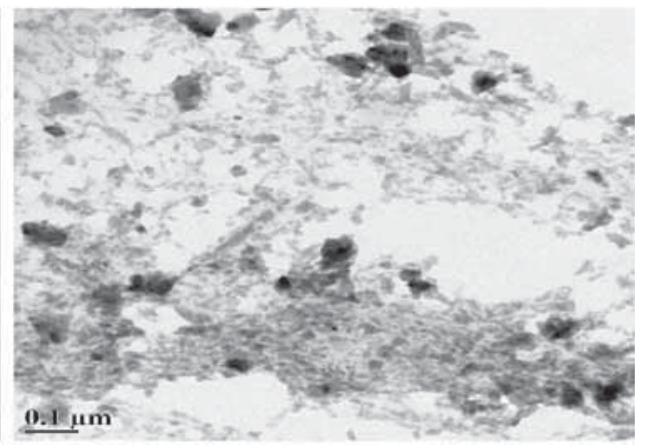

(b)

Figure 4. (a) Typical SEM image and (b) typical TEM image of the TAG co-doped powder sample.

\subsection{SEM/TEM images}

The nanostructure nature of the synthesized powder samples was investigated by SEM and TEM techniques. A typical SEM image is shown in figure $4 \mathrm{a}$, while a typical TEM image is shown in figure $4 \mathrm{~b}$. The nanostructure nature of the powder samples of TAG co-doped with $0.5 \mathrm{~mol} \% \mathrm{Ce}$ and $\mathrm{Eu}$ is clearly seen in the SEM and TEM images. Also, from the SEM image (figure 4a), it can be concluded that the synthesized powder sample was composed of spherically-shaped particles along with some non-spherical relatively large sized particles which could be due to agglomeration and/or strain induced by $\mathrm{Ce}$ and Eu doping. The spherical nature of the particles of the synthesized powder is further supported by the TEM images where spherical particles are clearly visible. Similar images were observed with other dopant combinations.

\section{$3.4 \quad F T I R$}

Typical FTIR spectra of TAG co-doped with Ce (0.1, 0.5 and $1.0 \mathrm{~mol} \%$, variable) and Eu (0.1 mol\%, constant) are

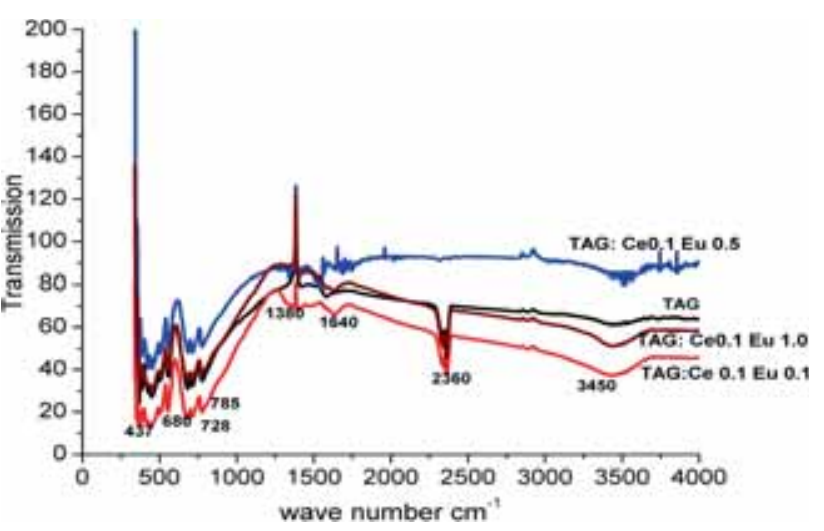

Figure 5. FTIR spectra of TAG co-doped with Ce $(0.1,0.5$ and $1.0 \mathrm{~mol} \%$, variable) and $\mathrm{Eu}(0.1 \mathrm{~mol} \%$, constant $)$.

shown in figure 5; the FTIR spectrum of TAG is shown in the same figure for comparison. All the samples were sintered at $1100^{\circ} \mathrm{C}$. The FTIR spectra were recorded in air using a $\mathrm{KBr}$ pellet. The observed absorption at 437, 680, 728 and $785 \mathrm{~cm}^{-1}$ could be due to $\mathrm{Tb}-\mathrm{O}, \mathrm{Ce}-\mathrm{O}$ and $\mathrm{Eu}-\mathrm{O}$ bonds while 


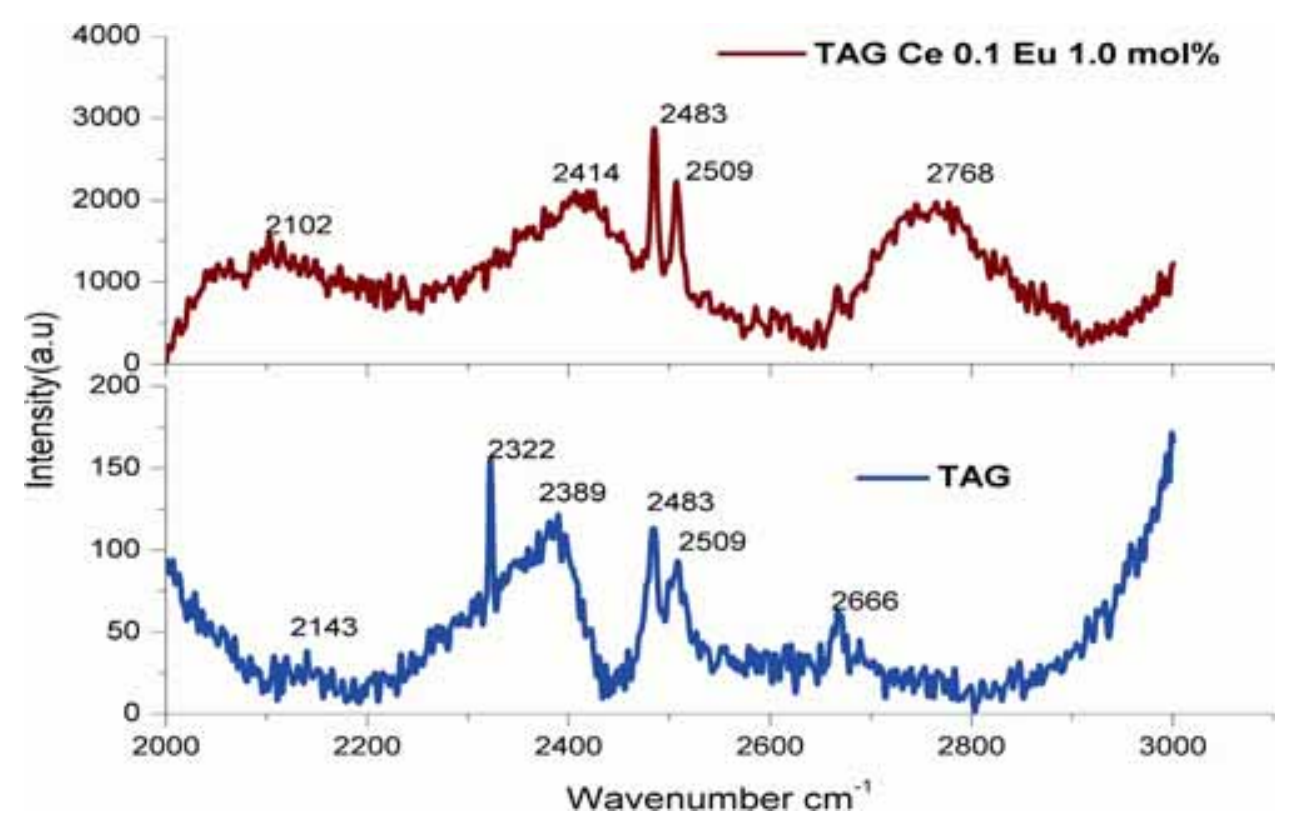

Figure 6. Typical room temperature Raman spectra of TAG and TAG:Ce $(0.1 \mathrm{~mol} \%)$ and Eu $(0.5 \mathrm{~mol} \%)$.

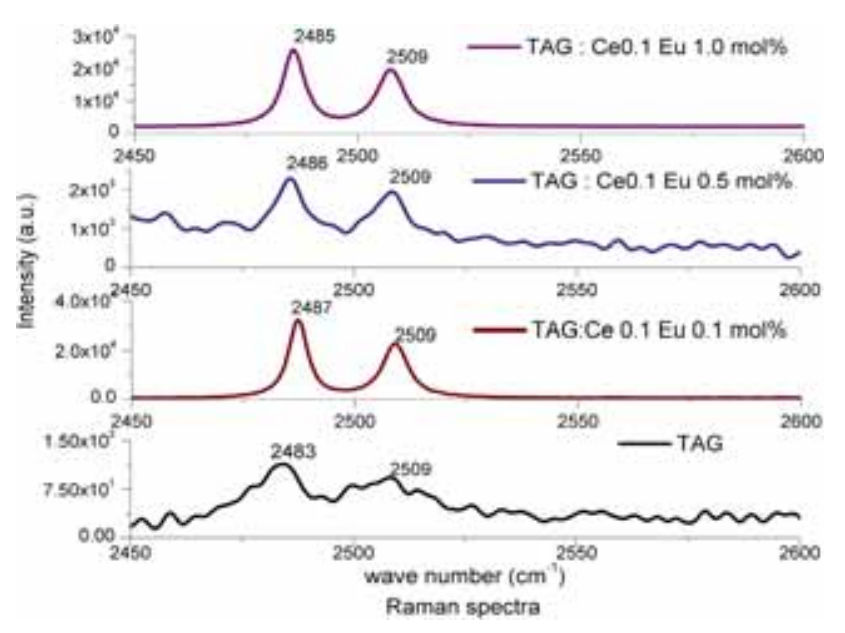

Figure 7. Raman shift in the peak position of $2483 \mathrm{~cm}^{-1}$ in Raman spectra as a function of dopant concentration.

relatively broad absorption at $3450 \mathrm{~cm}^{-1}$, which is typical of the $\mathrm{O}-\mathrm{H}$ functional group, could be due to water present in air. Similarly, 1380 and $1640 \mathrm{~cm}^{-1}$ absorption, which is typical of the $\mathrm{C}-\mathrm{O}$ functional group, could be attributed to $\mathrm{CO}_{2}$ present in air. The main spectral features of all the spectra shown in figure 5 are almost identical implying that the basic structure of TAG did not change on co-doping with $\mathrm{Ce}$ and Eu.

Spectral features similar to the results shown in figure 5 were observed for TAG co-doped with $\mathrm{Eu}(0.1,0.5$ and $1.0 \mathrm{~mol} \%$, variable) and Ce (0.1 mol\%, constant) as well as for TAG co-doped with $0.5 \mathrm{~mol} \% \mathrm{Ce}$ and $\mathrm{Eu}$.

\subsection{Raman scattering}

Typical Raman spectra of TAG and TAG:Ce $(0.1 \mathrm{~mol} \%)$ and Eu $(0.5 \mathrm{~mol} \%)$ are shown in figure 6 . As seen in this figure, Raman shifts at 2143, 2322, 2389, 2483, 2509 and $2666 \mathrm{~cm}^{-1}$ were observed in TAG when excited with $514.5 \mathrm{~nm}$ radiation from an Ar-ion laser. On doping with $0.1 \mathrm{~mol} \%$ of $\mathrm{Ce}$ and $0.5 \mathrm{~mol} \%$ of Eu, the peak position of the Raman shift at $2509 \mathrm{~cm}^{-1}$ did not change while it changed by $\sim 3 \mathrm{~cm}^{-1}$ in the case of the $2483 \mathrm{~cm}^{-1}$ shift. On the other hand, the shifts observed in TAG at 2143, 2322, 2389 and $2666 \mathrm{~cm}^{-1}$ were not observed in TAG:Ce $(0.1 \mathrm{~mol} \%)$ and $\mathrm{Eu}(0.5 \mathrm{~mol} \%)$; new shifts at 2102, 2414 and $2768 \mathrm{~cm}^{-1}$ were observed. In TAG, Raman shifts in undoped TAG are attributed to the electronic Raman of $\mathrm{Tb}^{3+}$ while in doped TAG, there could be contribution from $\mathrm{Ce}$ and Eu. Figure 6 shows the shift in the peak position of the Raman shift at $2483 \mathrm{~cm}^{-1}$ which is found both in TAG and in co-doped samples. As seen in figure 7, the peak position of the Raman shift at $2509 \mathrm{~cm}^{-1}$ did not change with the change in the dopant concentration while the other shifts at $2483 \mathrm{~cm}^{-1}$ changed by $\sim 4 \mathrm{~cm}^{-1}$ when TAG was co-doped with $0.1 \mathrm{~mol} \%$ of $\mathrm{Ce}$ and Eu. However, this shift was almost constant with the increase in the Eu concentration maintaining the Ce concentration constant at $0.1 \mathrm{~mol} \%$. However, the intensity showed significant variation (figure 8) where the integrated intensity area (arbitrary units) of the Raman shift at $2483 \mathrm{~cm}^{-1}$ has been plotted as a function of varying $(0.1,0.5$ and $1.0 \mathrm{~mol} \%)$ Eu concentrations while maintaining the Ce concentration constant at $0.1 \mathrm{~mol} \%$. As seen in this figure, the intensity of this Raman shift changed almost by two orders of magnitude when TAG was co-doped with $0.1 \mathrm{~mol} \%$ of $\mathrm{Ce}$ and Eu. However, the intensity reduced 


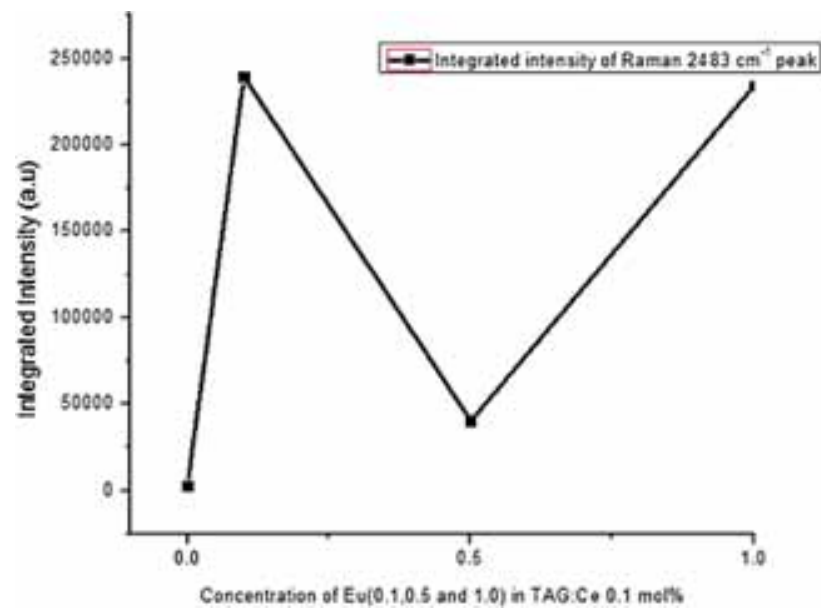

Figure 8. Intensity variation of the $2483 \mathrm{~cm}^{-1}$ Raman shift as a function of Eu concentration; the concentration of Ce was constant at $0.1 \mathrm{~mol} \%$.

almost by one order of magnitude when the Eu concentration was increased to $0.5 \mathrm{~mol} \%$ maintaining the Ce concentration at $0.1 \mathrm{~mol} \%$ while the intensity again changed by one order of magnitude when the Eu concentration was increased to $1.0 \mathrm{~mol} \%$ without changing the concentration of Ce which was kept constant at $0.1 \mathrm{~mol} \%$. The change in the intensity with $0.1 \mathrm{~mol} \%$ co-doping of $\mathrm{Ce}$ and Eu shows the distortion induced in the TAG lattice due to doping as Raman scattering is very sensitive to lattice distortion; this distortion is also reflected in the shifting of the peak position of the $2483 \mathrm{~cm}^{-1}$ Raman shift (figure 8). The subsequent variation in intensity could be due to the surface migration of Eu with an increase in its concentration. A similar type of behaviour was observed in TAG doped with $\mathrm{Ce}(0.1,0.5$ and 1.0 $\mathrm{mol} \%$, variable) maintaining the Eu concentration constant at $0.1 \mathrm{~mol} \%$.

\section{$3.6 U V-V I S$ absorption}

UV-VIS absorption spectra of TAG co-doped with Ce (0.1, 0.5 and $1.0 \mathrm{~mol} \%$, variable) and $\mathrm{Eu}(0.1 \mathrm{~mol} \%$, constant $)$ are shown in figure 9. TAG, as seen in this figure, has two absorption peaks at 228 and $280 \mathrm{~nm}$; both could be due to $\mathrm{Tb}^{3+}$. On co-doping with $0.1 \mathrm{~mol} \% \mathrm{Ce}$ and Eu, its TAG absorption in the UV region (200-250 nm) increased by a factor of $\sim 5$; also the intensity of the absorption peak at $280 \mathrm{~nm}$ increased marginally while showing almost zero absorption at $550 \mathrm{~nm}$. On the other hand, when Ce concentration was further increased to $0.5 \mathrm{~mol} \%$ maintaining the concentration of Eu constant at $0.1 \mathrm{~mol} \%$ a significant increase in absorption in the 200-350 nm region was observed; also an additional absorption peak at $380 \mathrm{~nm}$ was observed. This $380 \mathrm{~nm}$ absorption peak could be due to the $4 \mathrm{f}-5 \mathrm{~d}$ transition of $\mathrm{Ce}$. In the case of the TAG co-doped with $\mathrm{Ce}(1.0 \mathrm{~mol} \%)$ and $\mathrm{Eu}(0.1 \mathrm{~mol} \%)$, as seen in figure 9 , the absorption was almost uniform in the spectral region of $200-350 \mathrm{~nm}$, it peaked at $\sim 380 \mathrm{~nm}$ after

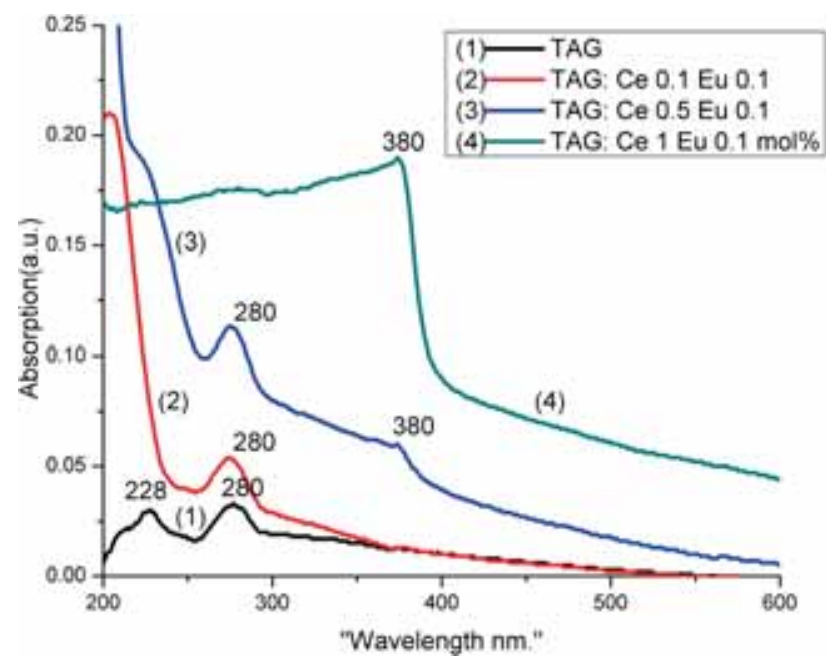

Figure 9. UV-VIS absorption spectra of TAG co-doped with Ce $(0.1,0.5$ and $1.0 \mathrm{~mol} \%$, variable $)$ and $\mathrm{Eu}(0.1 \mathrm{~mol} \%$, constant $)$.

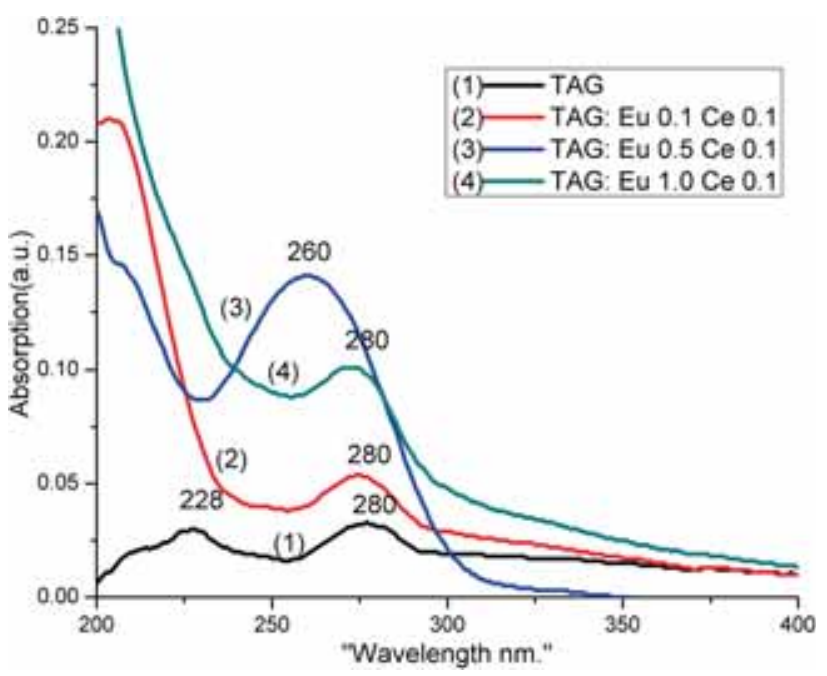

Figure 10. UV-VIS absorption spectra of TAG co-doped with Eu $(0.1,0.5$ and $1.0 \mathrm{~mol} \%$, variable $)$ and $\mathrm{Ce}(0.1 \mathrm{~mol} \%$, constant $)$.

which it decreased sharply till $\sim 400 \mathrm{~nm}$ and then decreased slowly; the absorption was significant even at $600 \mathrm{~nm}$. This observed absorption could be due to the $4 \mathrm{f}-5 \mathrm{~d}$ transitions of Ce. Figure 10 shows the UV-VIS absorption spectra of TAG co-doped with $\mathrm{Eu}(0.1,0.5$ and $1.0 \mathrm{~mol} \%$, variable) and $\mathrm{Ce}$ (0.1 mol\%, constant).

TAG when doped with $\mathrm{Ce}(0.1 \mathrm{~mol} \%)$ and $\mathrm{Eu}(0.5 \mathrm{~mol} \%)$, as seen in figure 10 showed broad absorption in the 225 $300 \mathrm{~nm}$ range with a peak at $260 \mathrm{~nm}$; this is characteristic Eu absorption. However, a decrease in absorption was observed in the 225 to $300 \mathrm{~nm}$ region where the peak shifted to $273 \mathrm{~nm}$ when the Eu concentration was increased to 1.0 mol\% implying the migration of Eu to the surface at higher concentrations. 

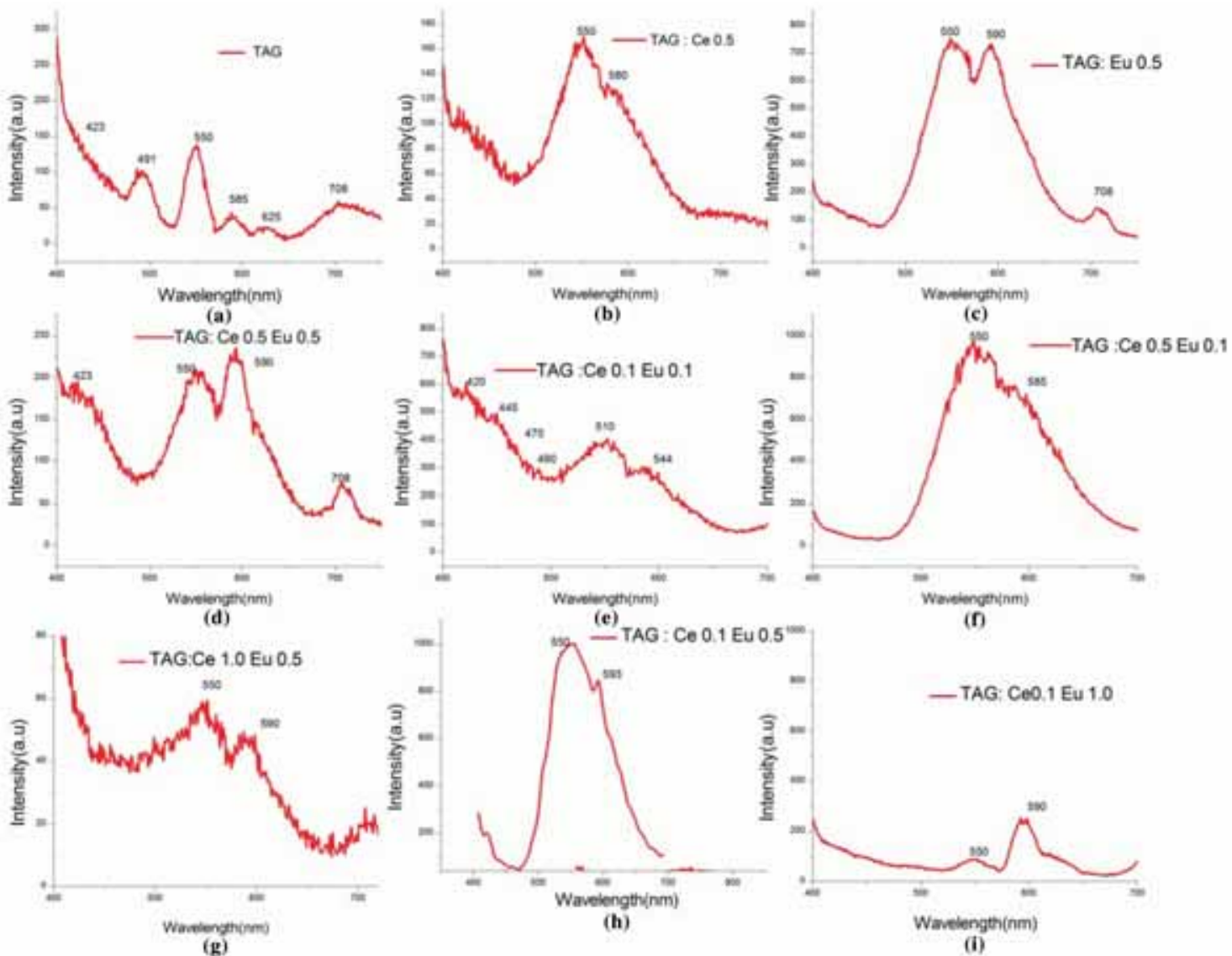

Figure 11. Emission spectra of (a) undoped TAG, (b \& c) Ce $0.5 \mathrm{~mol} \%$ and Eu $0.5 \mathrm{~mol} \%$ doped TAG and (d to i) Ce and Eu co-doped (mol\%) TAG powder excited by $280 \mathrm{~nm}$.

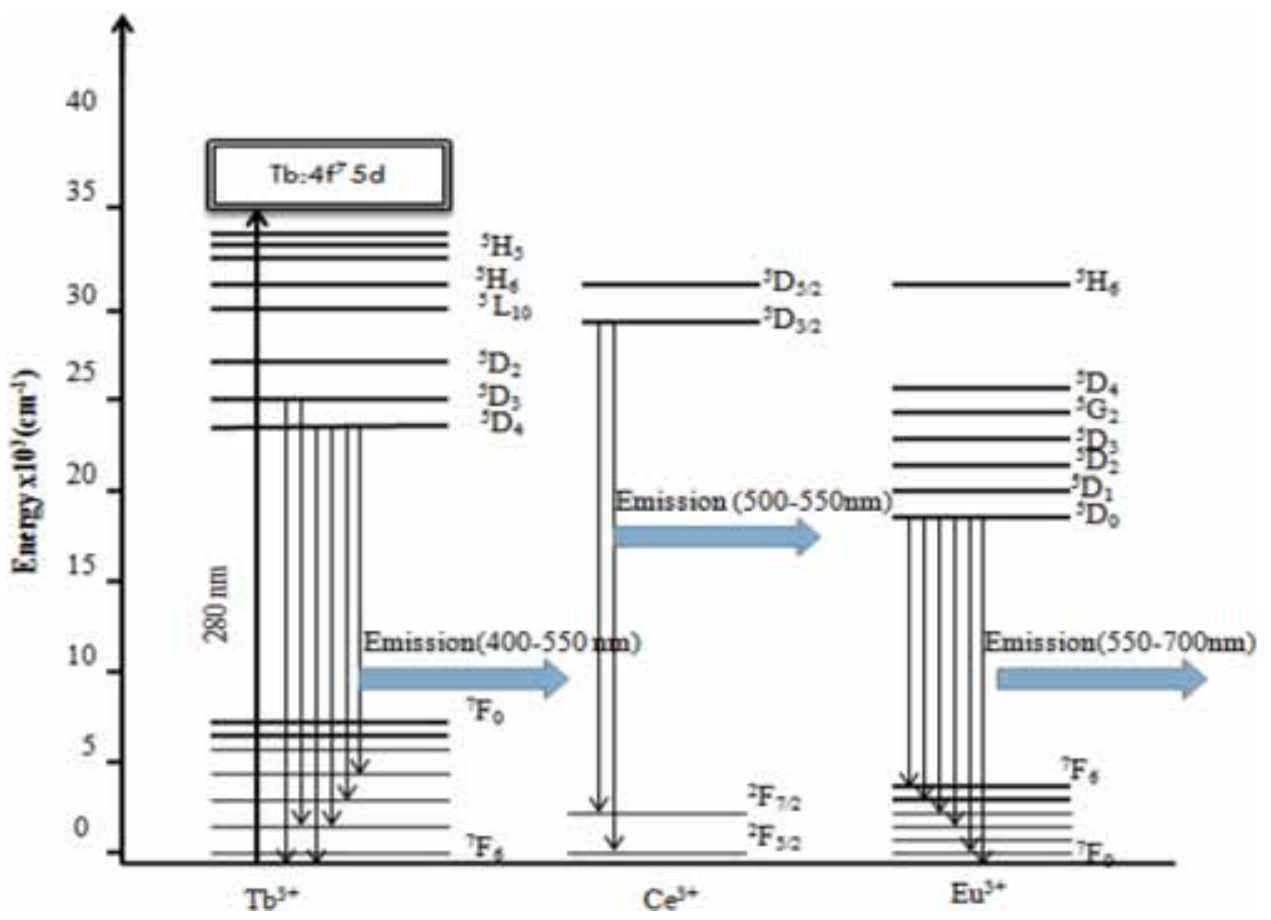

Figure 12. Transition lines of $\mathrm{Tb}^{3+}, \mathrm{Ce}^{3+}$ and $\mathrm{Eu}^{3+}$ ions. 


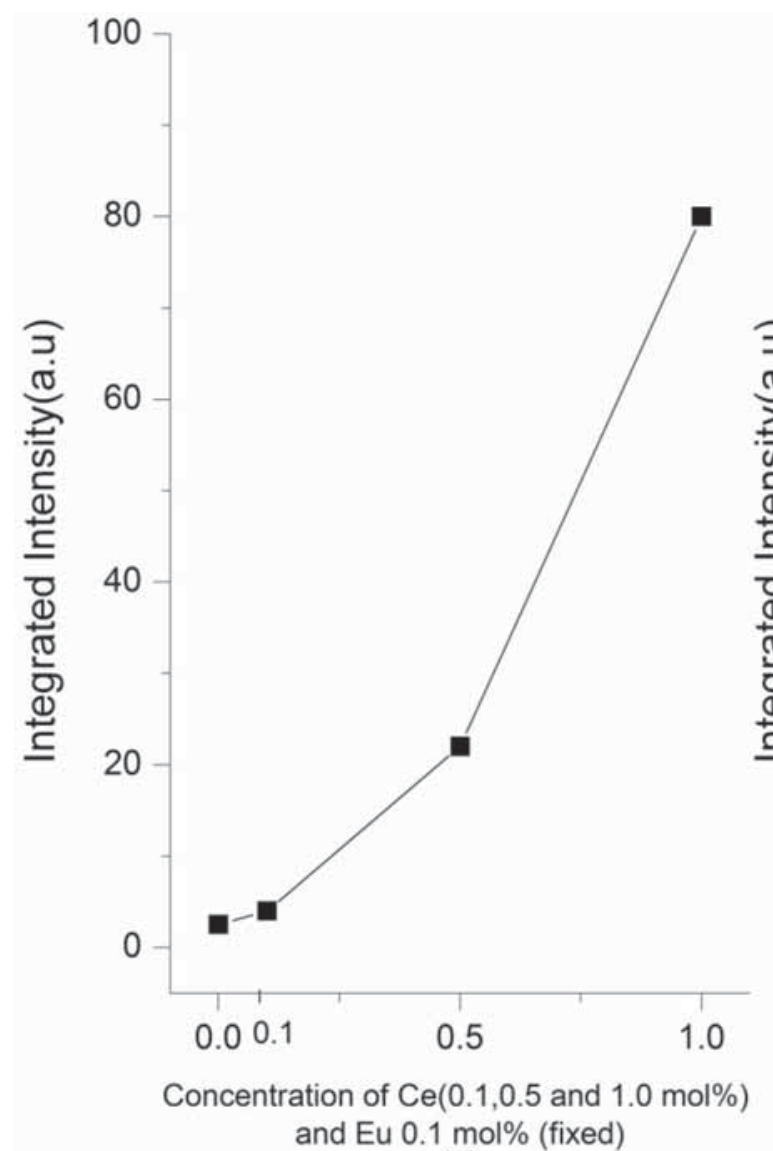

(a)

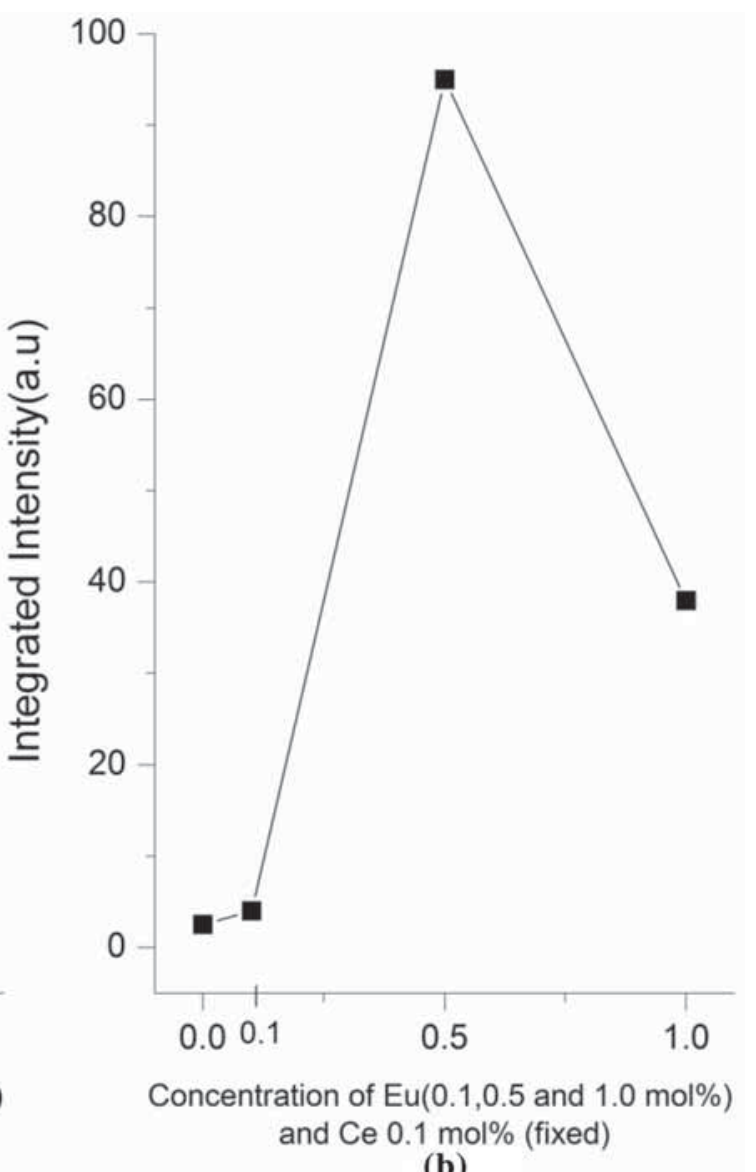

(b)

Figure 13. Integrated area (arbitrary units, au) of the emission spectrum of the TAG co-doped with (a) Ce $(0.1,0.5$ and $1.0 \mathrm{~mol} \%$, variable) and $\mathrm{Eu}(0.1 \mathrm{~mol} \%$, constant $)$ and (b) Eu (0.1, 0.5 and $1.0 \mathrm{~mol} \%$, variable) and Ce $(0.1 \mathrm{~mol} \%$, constant).

\subsection{Photoluminescence (PL)}

Figure 11 shows $280 \mathrm{~nm}$ excited PL spectra of TAG co-doped with $\mathrm{Ce}$ and $\mathrm{Eu}$; the spectra of single doped $\mathrm{Ce}$ and $\mathrm{Eu}$ and those of undoped TAG have been shown for comparison.

The PL of un-doped TAG, as seen in figure 11, consists of well-defined peaks in the visible regions which could be due to $\mathrm{Tb}^{3+}$ as shown in figure 12 . Relatively broad emission superimposed with a few peaks was observed when TAG was doped with $0.5 \mathrm{~mol} \% \mathrm{Ce}$. This broad emission could be due to the $5 \mathrm{~d}-4 \mathrm{f}$ emission of Ce while the superimposed peaks could be due to $\mathrm{Tb}$ present in TAG [17]. A similar type of broad emission was observed in TAG:Eu (0.5 mol\%) [18] and in TAG co-doped with $0.5 \mathrm{~mol} \%$ of both Ce and Eu. Emission lines from $\mathrm{Tb}$ are dominating in almost all the spectra except that of TAG co-doped with $0.1 \mathrm{~mol} \% \mathrm{Ce}$ and $1.0 \mathrm{~mol} \% \mathrm{Eu}$ where intensity falls sharply in the 400-500 nm region while $\mathrm{Tb}$ can be seen in the $500-700 \mathrm{~nm}$ region. This could be due to concentration quenching by Eu which has strong absorption in the 400-500 $\mathrm{nm}$ region. The variation in the intensity of the observed emission is shown in figure 11 where the integrated area (arbitrary units; au) of the emission spectrum has been plotted as a function of the dopant concentration (figure 13a and $b$ ).

The intensity of the emission in the visible region, as seen in figure 13a, increases significantly with the increase in the concentration of $\mathrm{Ce}$ maintaining the Eu concentration constant at $0.1 \mathrm{~mol} \%$. On the other hand, in the case of the TAG co-doped Eu $(0.1,0.5$ and $1.0 \mathrm{~mol} \%$, variable $)$ and $\mathrm{Ce}(0.1 \mathrm{~mol} \%$, constant), the intensity is maximum for $0.5 \mathrm{~mol} \%$ of Eu which decreases sharply when the Eu concentration is increased to $1.0 \mathrm{~mol} \%$ (figure 13b). This decrease with the increase in the Eu concentration could be due to 'concentration quenching' and/or due to increased distortion induced by Eu as discussed while analysing the XRD data.

The suitability of any phosphor material is assessed by calculating the chromaticity colour coordinates $(x, y)$ and colour correlated temperature (CCT) of its emission in the visible region [19]. Figure 14 summarizes these coordinates calculated for the visible emission observed from TAG co-doped with $\mathrm{Ce}$ and Eu.

TAG co-doped with $0.5 \mathrm{~mol} \%$ of both $\mathrm{Ce}$ and $\mathrm{Eu}$, as seen in figure 14, emits in the visible region which has characteristics of 'day light' indicating its utility in the realization of white 


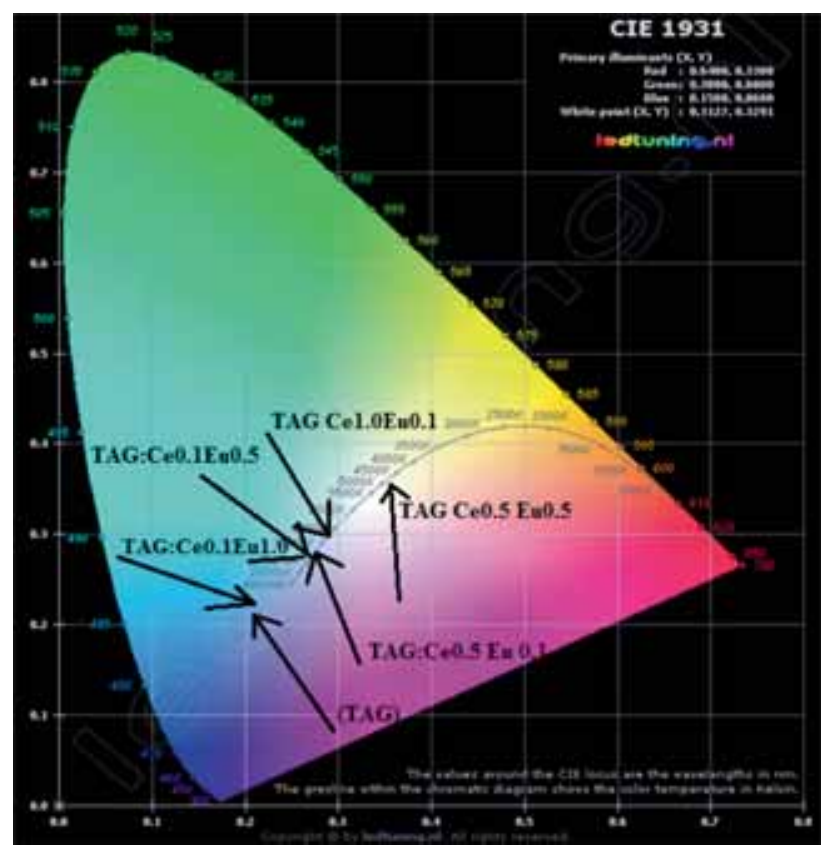

Figure 14. CIE diagram of TAG co-doped with Ce and Eu.

light sources; its chromaticity colour coordinates $x=0.35$ and $y=0.35$ along with CCT $=4812 \mathrm{~K}$ are very close to that of an ideal white light source which should have $x=0.33$ and $y=0.33$ with CCT $=\sim 5000 \mathrm{~K}$. On the other hand, CIE coordinates of TAG with different doping concentrations of $\mathrm{Ce}$ and $\mathrm{Eu}$ are marked on the CIE diagram [20] as shown in figure 14, emit blue-purple or blue-green shades and can be used for the fabrication of coloured light sources. However, its colour rendering index needs to be investigated to realize its full potential.

As seen in figure 14, the emission falls very well in the white light region of the CIE diagram.

\section{Conclusion}

Undoped and co-doped TAG were excited by $280 \mathrm{~nm}$ and show broad emission in the visible region. The PL spectra of undoped TAG consist of well-defined peaks in the visible regions which are due to $\mathrm{Tb}^{3+}$. TAG:Ce $(0.5 \mathrm{~mol} \%)$ showed broad emission in the visible region which could be due to the $5 \mathrm{~d}-4 \mathrm{f}$ emission of $\mathrm{Ce}$ along with the superimposed peaks due to Tb present in TAG. Similar broad emission was observed in TAG:Eu ( $0.5 \mathrm{~mol} \%)$ and in TAG co-doped with $0.5 \mathrm{~mol} \%$ of both $\mathrm{Ce}$ and $\mathrm{Eu}$. TAG co-doped with $0.5 \mathrm{~mol} \%$ of both $\mathrm{Ce}$ and $\mathrm{Eu}$ emits in the visible region which has characteristics of 'day light' indicating its utility in the realization of white light sources; its chromaticity colour coordinates $x=0.35$ and $y=0.35$ along with CCT $=4812 \mathrm{~K}$ are very close to that of an ideal white light source which should have $x=0.33$ and $y=0.33$ with $\mathrm{CCT}=\sim 5000 \mathrm{~K}$.

\section{References}

[1] Van der Burgt P and Van Kemenade J 2010 Color Res. Appl. 3585

[2] Chiang C C, Tsai M S and Hon M H 2007 J. Electrochem. Soc. 155 B 517

[3] Jung K Y and Lee H W 2007 J. Lumin. 126469

[4] Chen Y, Wang J, Gong M and Su Q 2007 J. Solid State Chem. 1801165

[5] Yong P, Ke T, Da-Chuan Z, Tao H, Cong Z and Ling-Ling P 2013 Nano Micro Lett. 5117

[6] Nazarov M and Noh D Y 2010 J. Rare Earths 281

[7] Ganschow S, Klimm D, Reiche P and Uecker R 1999 Cryst. Res. Technol. 34615

[8] Saxena S, Asokkumar A K and Lal B 2007 J. Sol. Gel. Sci. Technol. $\mathbf{4 1} 245$

[9] Shabir H, Lal B and Rafat M 2010 Ceram. Int. 36365

[10] Kim J S, Jeon P E, Park Y H, Choi J C, Park H L, Kim G C et al 2004 Appl. Phys. Lett. 853696

[11] Yao G Q, Lin J H, Zhang L, Lu G X, Gong M L and Su M Z 1998 J. Mater. Chem. 8585

[12] Shabir H, Lal B and Rafat M 2010 J. Sol. Gel. Sci. Technol. 53 399

[13] Chiang C C, Tsai M S and Hon M H 2007 J. Alloy. Compd. 431298

[14] Dotsenko V P, Berezovskaya I V, Poletaev I N, Doroshenko Yu A, Zadneprovski B I, Efryushina N P et al 2013 J. Alloys Compd. 550159

[15] Batentschuk M, Osvet A, Schierning G, Klier A, Schneider J and Winnacker A 2004 Radiat. Meas. 38539

[16] Ye S, Wang X M and Jing X P 2008 J. Electrochem. Soc. 155 J143

[17] Xia Z and Meijerink A 2017 Chem. Soc. Rev. 46275

[18] Hammami S, Boudjada N C and Megriche A 2018 Int. J. Anal. Chem. 20184371064

[19] McCamy and Calvin S 1992 J. Colour Res. Appl. 17142

[20] The CIE 1931 color space chromaticity diagram. https://www. ledtuning.nl/en/cie-convertor (accessed on 20/07/18) 